\title{
PRIMEROS PASOS \\ DE LA ORDEN MILITAR DEL TEMPLE EN CATALUÑA
}

\author{
JOSE ENRIQUE RUIZ-DOMÈNEC \\ Universitat Autònoma de Barcelona
}

\begin{abstract}
Cuando la altiva Beatriu de Montcada elevó al arzobispo de Tarragona los motivos que tenía para pedir el divorcio del influyente Guillem Ramon, el Gran Senescal de Barcelona (con el que se había casado en 1117) no era consciente de la importancia de la misión que su marido estaba realizando para el futuro de Cataluña en nombre del conde Ramon Berenguer IV. Pero esa gran dama era muy formalista y estaba completamente convencida que la vida matrimonial estaba por encima de las obligaciones políticas. Los sucesos se precipitaron y luego las interpretaciones modernas, no todas adecuadas a lo que nos dicen los documentos de la época.

He recordado esa pequeña anécdota de la alta política catalana de los años treinta del siglo XII releyendo las magníficas investigaciones de Regina Sainz de la Maza. Su lenguaje preciso y su rigor se inscribe en lo mejor de la gran tradición del medievalismo europeo, en la que ella había sido una de sus figuras más señeras. Uno de los temas por los que sentía predilección era sin duda la activa presencia de las Ordenes Militares en la arquitectura económica, jurídica y política de la Península Ibérica durante la Edad Media.

Como homenaje a su labor me ha parecido oportuno ofrecer a continuación unas breves reflexiones sobre los primeros pasos de la orden del Temple en Cataluña: el gran aprecio que sentía por Regina Sainz de la Maza me legitima esta osadía. Espero que se comprenda.
\end{abstract}

"Anuario de Estudios Medievales", 28 (1998) 
En abril de 1134, durante los tres días en que por casualidad coincidió la aceptación por parte de Oleguer arzobispo de Tarragona de las Ordenes Militares en el suelo catalán (el día 14$)^{1}$ y el testamento del viejo Berenguer de Montcada donde dejaba sus propiedades por igual a su hija Beatriu y a su yerno el senescal Guillem Ramon ${ }^{2}$, la sociedad catalana estaba a punto de contemplar uno de los sucesos más trascedentales de su historia sin apenas ser consciente. La mezcla de ambos sucesos fascina al actual observador del pasado: el escenario de la gran historia mediterránea, con la imparable progresión de los ideales militares que desde Palestina (Tierra Santa para los cruzados) había comenzado a llegar como un feed back de la conquista de Jerusalén en Julio de 1099, se entrecruza con una historia local, un pequeño y al parecer insignificante asunto familiar, aunque afectara a uno de los linajes más importantes de la Cataluña de aquel tiempo. ¿Qué historia nos interesa? ¿Acaso los complejos entramados político-religiosos que hicieron posible el asentamiento del Temple en Cataluña o los motivos por los que Beatriu de Montcada, una vez ha heredado los bienes patrimoniales de su linaje, reclama ante el arzobispo de Tarragona el divorcio de su marido? ${ }^{3}$

No me preocuparía de este cruce entre los dos planos de la historia sino fuera porque uno de los personajes implicados, el Gran Senescal Guillem Ramon, está presente en ambos escenarios. Lo está en el proceso de asentamiento del Temple en Cataluña (esa era la razón de su ausencia, cosa que Beatriu no sabía), pues Ramon Bereguer IV ha pedido a diez de sus hombres de confianza (un gesto propio de la cultura feudal) que permanezcan un año en la casa del Temple, viendo quienes son, cómo actuan, qué desean $^{4}$. Son sus consejeros. Un año viviendo como monjes montaraces, célibes y soldados. Pero, al mismo tiempo, y porque lo que hacía el Gran Senescal era al servicio de su amigo el conde de Barcelona y a la nación catalana, ese acto fue el detonante para que su esposa pidiera el inmediato divorcio.

'ACA, Cancillería, perg. Ramon Berenguer IV, núm. 28.

${ }^{2}$ ACA, Cancillería, perg. Ramon Berenguer IV. núm. 29.

${ }^{3} \mathrm{ACA}$, Cancillería, perg. Ramon Berenguer IV, núm. 63.

${ }^{4} \mathrm{ACA}$, Cancillería, perg. Ramon Berenguer IV, núm. 28: "Promitit [Raimundus comes Barchinonensis] se Guillelmo Raimundo Senescali et frater ejus Oto stare in servicio Dei in ipsa cavalleria de grana uno anno...". 
Guillem Ramon no se opuso, pues pensó que su matrimonio representaba una dificultad a la hora de poner en marcha los planes políticos de su amigo y señor, el conde de Barcelona. La amistad por encima del amor. Un gesto feudal. Beatriu no era buena conocedora de la política de Estado como para prever la silenciosa satisfacción que con ello le proporcionaba a su marido el Gran Senescal.

En cuanto Beatriu protesta, Guillem Ramon se siente aliviado, y entonces ella no tiene otra salida que huir hacia adelante y pedir el divorcio que, desde luego, el arzobispo no duda en darselo presionado por el propio conde de Barcelona, y nosotros intuimos que en esa celeridad había una clara complicidad entre los dos viejos amigos, el conde y el senescal.

Para comprender la situación creada no debemos olvidar algo importante: Guillem Ramon era desde su juventud un hombre importante en la politica catalana; cuando conoció a Beatriu su padre ya hacía muchos años que había establecido el cargo de senescal en el seno de su familia: en realidad lo había conseguido entre entre 1068-1072 tras su asentamiento en la ciudad ${ }^{5}$. Luego, en 1122 , a la muerte de su padre 6 , sólo quedaba él para acompañar al nuevo conde Ramon Berenguer IV en los grandes proyectos del Estado: la conquista de las Taifas de Lleida y Tortosa, para lo cual las ordenes militares eran decisivas. Por eso, cuando comprendió que el asentamiento era definitivo, y que los obispos apoyaban la iniciativa, pensó con alivió que su cautela ya no iba a ser necesaria, y que cualquier movimiento de su mujer en contra de él no tendría ninguna trascendencia ulterior. Además de eso, el testamento de Berenguer de Montcada (17 de Abril de 1134) dejaba claro que él era el heredero de la mitad de los bienes del linaje, y que su hijo (su única y verdadera preocupación) llevaría el título de Montcada. Lo que consigue también al modo feudal: haciendo que los milites de la casa Montcada "serviant Guilelmi Raimundi, el hijo, y además sint sui et habeas eos solidos"7. El asunto parecía bien acabado. Eso hizo que ambos amigos, el conde y el senescal, estuviesen de buen humor preocupados tan solo por esos nuevos inquilinos: el Temple

Apenas una semana después de ese difícil cruce entre la gran y la pequeña historia, la orden del Temple declara abiertamente sus intenciones

\footnotetext{
${ }^{5}$ ACA, Cancillería, perg. Ramon Berenguer I, sin fecha num. 448.

${ }^{6} \mathrm{Su}$ testamento del 17-XI-1112 en ACA, Monacales, Amer, núm. 14.

${ }^{7} \mathrm{ACA}$, Cancillería, perg. Ramon Berenguer IV, núm. 63.
} 
y su inmensa capacidad de observación. Un viejo cives de Barcelona, de nombre Bernat Ramon, llamado el Maçanet, toma una importante decisión en su vida ${ }^{8}$. Concede a la milicia del Temple la mitad de sus casas "cum muro et turribus et curtello et puteo", que están "in muris civitatis Barchinone", cerca del Castillo de Regomir, donde se solían construir naves. Era sin duda el mejor sitio entonces en la ciudad de Barcelona: allí tenían los condes un palacio, y estaba la casa de quien había sido uno de los ciudanos más ricos (en efecto los textos le llamaban dives) de Barcelona Bernat Ramon; también en ese lugar se levantaba la inmensa vivienda de los herederos de Ricard Guillem, el personaje más influyente de Barcelona a comienzos del siglo XII, íntimo amigo de Ramon Berenguer III y de Dolça de Provenza, su mentor en cuestiones de economía y finanzas: el verdadero artífice de la ciudad de Barcelona ${ }^{9}$. Los hermanos del Temple habían sabido elegir bien: se situaban en el centro mismo de las decisiones políticas, económicas y culturales de la ciudad, que era tanto como decir del país.

Todo eso ocurría ante los ojos de una nobleza atónita por los cambios de la Historia: ojos como los de Beatriu de Montcada que nunca entendió quienes eran sus nuevos vecinos, pese a que indirectamente fueron ellos los responsables de su divorcio. Debilitada por su decisión y por el temor de que su divorcio pudiera alejarla de la corte condal, obedeció. El astuto Ramon Berenguer IV consiguió desactivarla como se desactiva una bomba.

Luego, en octubre de 1136, el conde Ramon Berenguer IV escogió a un hombre de su confianza, nada peligroso, Guillem de San Martí, y le dio como esposa (in uxorem) a la altiva Beatriu ${ }^{10}$. No hubo nada más alegre en la vida de esta mujer, ya entrada en años, que este matrimonio con el taciturno Guillem: Beatriu está desarmada y ya no da miedo. El conde tiene las manos libres para poner orden en la sociedad aristocrática. Necesita ese orden para concentrar sus objetivos matrimoniales con la reina de Aragón, la niña Petronila, que Ramiro II había tenido de Agnès de Poitou, la nieta de Guilhem de Peitieu, el trovador, cosa que al final consigue el 11 de

\footnotetext{
${ }^{8}$ ACA, Cancillería, perg. Ramon Berenguer IV, núm. 31.

9J.E. RUIZ-DomĖnEC, Ricard Guillem: un sogno per Barcellona, Napoli, Athenea, 1999.

${ }^{10} \mathrm{ACA}$, Cancillería, perg. Ramon Berenguer IV, núm. 50: "Concedit namque et laudat jamdictus comes Raimundus prelibato Guilemo dompnam Beatricem in uxorem..."
} 
agosto de $1137^{11}$. De Beatriu nunca más se supo, probablemente vivió el resto de su existencia junto a su Guillem, cerca de la corte, intentando no mostrar su cólera ante el prodigioso ascenso de su exmarido el Gran Senescal, y el distanciamiento crítico de su hijo que terminó por contraer matrimonio con María de Bearn, heredando con ello aquel bello y rico territorio. Quizás en algún momento se sintió abrumada, pero la historia nunca más pasó por su lado. La olvidó. ¿Y al Temple?

Al Temple desde luego no. La Orden Militar del Temple se había instalado en la frontera gracias a la donación del santo arzobispo Oleguer, en la ciudad gracias a la donación del atormentado ciudadano Bernat Ramon, el Maçanet, y lo había hecho en silencio, sin mostrar sus verdaderas intenciones. El ruido lo había dejado para los actos de Beatriu de Montcada y sus infundados celos hacia el Gran Senescal.

No revelo el final de esta historia; simplemente llamo la atención sobre el giro extraordinario que la instalación del Temple provocó en la sociedad catalana. El Gran Senescal, claro, convirtió esa instalación de forma consciente en un beneficio para sí mismo y sus descendientes. Beatriu de Montaca no es una adúltera y provinciana esposa es el ejemplo supremo de una dama aristocrática del siglo XII aferrada a los valores del pasado en un mundo que caminaba clara e irremediablemente en la línea anunciada por la respuesta que Eloísa le había dado a su maestro Abelardo, justo cinco años antes de todo este intricado asunto.

La moraleja es clara: la milicia del Temple consiguió su instalación en Cataluña sin que ese crucial suceso histórico fuera percibido por sus habitantes, atentos al escándalo por lo que había ocurrido entre la Montcada y el Senescal.

\section{RÉSUMÉ}

L'année 1134, l'archêveque de Tarragona, Oleguer, autorise l'installation des Ordres Militaires à la Catalogne. L'article étudie la participation de Guillem Ramon de Montcada dans l'affaire et sa relation avec son divorce de Beatriu de Montcada.

\footnotetext{
"ACA, Cancillería, perg. Ramon Berenguer IV, num. 86.
} 


\section{SUMMARY}

In 1134, Oleguer, archbishop of Tarragona, approve Military Orders' intallation at Catalonia. This paper studies the role of Guillem Ramon de Montcada in this matter and its relation with his divorce from Beatriu de Montcada. 